\title{
(t)
}

\section{AS POLÍTICAS INDIGENISTAS E AS LUTAS SOCIAIS INDÍGENAS: MANIFESTAÇÕES DA QUESTÃO SOCIAL}

\author{
INDIGENOUS POLICIES AND INDIGENOUS SOCIAL STRUGGLES: MANIFESTATIONS OF THE \\ SOCIAL QUESTION
}

\author{
Rosa Maria Castilhos Fernandes* \\ http://orcid.org/0000-0001-5499-714X \\ Mariana Martins Maciel ${ }^{* *}$ \\ https://orcid.org/0000-0001-9406-9196
}

\begin{abstract}
RESUMO
O artigo discorre sobre as lutas sociais indígenas como forma de resistência diante das violações de seus direitos e como sendo expressão da questão social. Procura dar visibilidade às políticas indigenistas uma vez que os ataques a esses povos também têm relação à destituição de um conjunto de legislações no âmbito da proteção social brasileira. Destaca a emergência desta discussão no âmbito do Serviço Social.
\end{abstract}

\section{PALAVRAS CHAVE}

Lutas Sociais. Indígenas. Questão Social. Políticas Indigenistas.

\section{ABSTRACT}

The article discusses indigenous social struggles as a form of resistance to violations of their rights and as an expression of social issues. It seeks to give visibility to indigenous policies since the attacks on these peoples are also related to the destitution of a set of legislations within the scope of Brazilian social protection. It highlights the emergence of this discussion within the social work.

\section{KEYWORDS}

Social Struggles. Indigenous. Social Issues. Indigenist Policies.

Submetido em: 28/8/2019.

Aceito em: 9/12/2019.

\section{INTRODUÇÃO}

á faz algum tempo que a questão indígena vem provocando diferentes reflexões no ambiente acadêmico e, nos últimos anos, mais precisamente com a inclusão de indígenas na educação superior por meio da lei de cotas - Lei Federal $n^{\circ} 12.711$, de 29 de agosto de 2012 (BRASIL, 2012), o que tem despertado debates com relação à diversidade cultural, ao estranhamento com relação aos modos de ser e viver dos estudantes indígenas, assim como, de suas formas de conhecer e interagir neste território, entre tantos outros aspectos. É preciso reconhecer que essas ações afirmativas vêm atender às

\footnotetext{
* Assistente Social. Doutora em Serviço Social. Professora e Pesquisadora do Departamento de Serviço Social e do PPG Política Social e Serviço Social da Universidade Federal do Rio Grande do Sul (UFRGS, Porto Alegre, Brasil). Av. Paulo Gama, 110 - Farroupilha, Porto Alegre (RS), CEP.: 90040-060. E-mail: <rmariacf@uol.com.br>. ** Bacharel e Licenciada em Geografia. Professora de Escola Indígena. Mestranda do PPG Política Social e Serviço Social da Universidade Federal do Rio Grande do Sul (UFRGS, Porto Alegre, Brasil). Av. Paulo Gama, 110 - Farroupilha, Porto Alegre (RS), CEP.: 90040-060. E-mail: <mari2ommaciel@yahoo.com.br>.
}

Temporalis, Brasília (DF), ano 19, n. 38, p. 70-86, jul./dez. 2019. | ISSN 2238-1856 


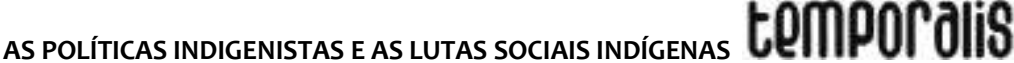

lutas históricas de povos como os indígenas, os afro-brasileiros, ou ainda os estudantes de escolas públicas e de baixa renda que ficaram por décadas de fora dos processos educativos por conta da lógica neoliberal, da competitividade e do discurso do mérito. Lógica esta que desponta com toda força no cenário atual brasileiro com a guinada da direita ao poder e na condução das políticas sociais brasileiras, que vêm sendo desfalcadas cotidianamente.

De fato, são mudanças que exigem um repensar coletivo para que se possa desvendar o que está por trás dos limites da permanência desses estudantes na educação superior, o significado das lutas sociais da qual fazem parte, das suas necessidades humanas, das violações de direitos e dos preconceitos cotidianos, principalmente, quando saem das suas comunidades de origem, reconhecidas como aldeias, entre outros aspectos, que vão caracterizar as múltiplas expressões da questão social que esses coletivos vivenciam (FERNANDES; AMES; DOMINGOS, 2017). De acordo com o último Censo da Educação Superior do Instituto Nacional de Estudos e Pesquisas Educacionais Anísio Teixeira (INEP), estima-se que em 2016, 56,7 mil indígenas, estavam matriculados no ensino superior do país (INSTITUTO NACIONAL DE ESTUDOS E PESQUISAS EDUCACIONAIS ANÍSIO TEIXEIRA, 2016). No Brasil existem 817.963 indígenas que se dividem em 305 etnias e 274 línguas, sendo que destas 315.180 vivem em cidades e 502.783 em áreas rurais, o que corresponde a $0,42 \%$ da população do país (INSTITUTO BRASILEIRO DE GEOGRAFIA E ESTATÍSTICA, 2010). A Fundação Nacional do Índio (FUNAI), também registra 69 referências de índios ainda não contatados, além de grupos que estão requerendo o reconhecimento de sua condição indígena junto ao órgão federal indigenista.

É então diante deste cenário, que destacamos a necessária aproximação da realidade dos povos indígenas. Estudos desenvolvidos no ambiente acadêmico revelam que a percepção dos não-indígenas e dos indígenas, que os modos de ser, conhecer e viver desses coletivos estão relacionados: à natureza, à sua vinculação aos chamados povos originários, ao pertencimento às suas culturas, ao reconhecimento ou não como sendo sujeitos de direitos, à discriminação e ao sofrimento vivido ao longo de décadas e, fundamentalmente, com as suas resistências e lutas cotidianas (FERNANDES, 2018).

Entretanto, são evidentes as contradições construídas social e historicamente com relação a esses povos, que vão desde o preconceito ao reconhecimento, do estranhamento à naturalização, entre outros aspectos. Neste sentido, entendemos que as investigações e estudos que tenham como temática a causa indígena, são uma maneira de construir conhecimentos científicos que, fundamentalmente, estejam a serviço da construção de uma sociedade que possibilite a emancipação política e humana, tão necessária diante dos ataques neocolonizadores e do capital financeiro que vêm demarcando a liberdade dos povos.

Na história que se desenrola neste século XXI são inúmeros os desafios, ainda obscuros, para os diversos setores que englobam a temática indígena incluindo as políticas sociais, que devem a partir de seus programas e serviços atender os direitos dos povos indígenas em todo território nacional. Não são poucas as notícias que visualizamos na mídia sejam elas nos meios de comunicação de massa ou alternativos, assim como, nos relatos trazidos pelos estudantes indígenas universitários e pelas suas lideranças, sobre os ataques às etnias indígenas, que vêm ocorrendo e que violam os direitos humanos.

Temporalis, Brasília (DF), ano 19, n. 38, p. 70-86, jul./dez. 2019. | ISSN 2238-1856 
É de conhecimento que os direitos indígenas vêm sendo ameaçados historicamente, porém, esses povos enfrentam atualmente riscos mais graves do que em qualquer outro momento desde a Constituição Federal brasileira de 1988 (CF/88). De acordo com o relatório apresentado ao Conselho de Direitos Humanos pela relatora especial da Organizações das Nacões Unidas (ONU), que tratou também dos direitos dos povos indígenas, Victoria Taulino, "[...] o atual contexto político, as ameaças que esses povos enfrentam podem ser exacerbadas e a proteção de longa data de seus direitos pode estar em risco" (ORGANIZAÇÕES DAS NACÕES UNIDAS, 2016, p. 1).

Entre os exemplos mais recentes estão as manifestações que circularam durante a campanha do atual presidente do Brasil como o dito: nenhum centímetro de terra a mais para os indígenas, assim como, enquanto eu for presidente, não tem demarcação de terra indígena argumentando ainda "[...] que os indígenas já possuem 14\% do território nacional demarcado e que já é o suficiente" (PUTTI, 2019). Isso posto, várias medidas têm sido tomadas tais como, a retirada da demarcação de terras indígenas da FUNAI, submetendo ao Ministério da Agricultura que é naturalmente alinhado com interesses do agronegócio, parte deste setor em conflito permanente com os interesses indígenas, assim como, as iniciativas que vêm se desenhando para que a mineração e a exploração das terras indígenas na região da Amazônia, possam ocorrer por meio de editais abrindo para o mercado financeiro e empresas multinacionais. Ainda em 2014, a Proposta de Emenda Constitucional- PEC 215 que tinha a intenção de delegar exclusivamente ao Congresso Nacional o dever de demarcação de territórios indígenas e quilombolas, bem como a ratificação de área já aprovada, mobilizou indígenas de diversas regiões do Brasil que protestaram em frente à Câmara para impedir a sua votação.

De lá para cá as ofensivas só pioraram para os povos indígenas. É o Estado brasileiro se contrapondo às lutas históricas pela demarcação de terras indígenas, por meio de medidas nada democráticas e arbitrárias. Não existem evidências de respeito à consulta necessária aos povos indígenas, pois de acordo com o estabelecido pela Convenção 169 da Organização Internacional do Trabalho, da qual o Brasil é signatário, o artigo $6^{\circ}$ obriga 0 governo "[...] consultar os povos interessados, mediante procedimentos apropriados e, particularmente, através de suas instituições representativas, cada vez que sejam previstas medidas legislativas ou administrativas suscetíveis de afetá-los diretamente" (BRASIL, 2004a). Como diz lamamoto é "[...] na raiz do atual perfil assumido pela questão social que encontram-se as políticas governamentais favorecedoras da esfera financeira e do grande capital produtivo [...]" (IAMAMOTO, 2008, p. 124).

Segundo o Instituto Socioambiental (2018), no Brasil cerca de 1 milhão de indígenas de mais de 250 etnias distintas vivem em 13,8\% do território nacional, revelando o baixo percentual de Terras Indígenas (TIs) demarcadas e as causas do acirramento dos conflitos fundiários decorrentes de interesses opostos do agronegócio em relação aos Povos Indígenas. Ainda, muito dos laudos de demarcação de terras da FUNAI estão sendo recusados pela Justiça Brasileira, em função de interesses ruralistas.

Neste contexto e no contraponto, é por meio da luta que os indígenas tentam resistir à lógica ultraliberal do capital. Por isto, nos interessa dar visibilidade neste texto sobre as diferentes manifestações da questão social vivenciadas por esta população, sejam os ataques e violações que sofrem ou, sejam as suas lutas e mobilizações sociais, que se espalham pelo Brasil afora fazendo com que diferentes etnias se unam e dialoguem numa

Temporalis, Brasília (DF), ano 19, n. 38, p. 70-86, jul./dez. 2019. | ISSN 2238-1856 
luta única, dando sentido às suas experiências de resistências enquanto povos originários em defesa dos territórios e das políticas indigenistas.

O período vivenciado tem sido de transformações da sociedade brasileira e de toda ordem, resultando na descaracterização da seguridade social como direito, ou ainda, dos processos democráticos e de participação social como a extinção de conselhos de diferentes segmentos sociais, incluindo o dos indígenas. Assim sendo, um dos principais desafios dos povos indígenas, é a constante afirmação na sociedade por meio da garantia de seus direitos. Apesar do processo de democratização a partir da CF/88, ter estabelecido um novo paradigma sobre os direitos dos povos originários, rompendo com a perspectiva tutelar e integracionista, a concretização dessa ruptura ainda é um processo em curso e requer a ampliação do diálogo sobre a temática.

Este cenário nos convoca para pensar o quanto ainda se faz necessário deflagrar este debate no âmbito da sociedade, nas Universidades trazendo para seus currículos- diga-se em diferentes cursos - as pautas indígenas, como por exemplo, as políticas indigenistas que estão inseridas nas políticas de proteção social como na saúde, na assistência social, na educação e na previdência social. Da mesma forma, esta pauta deve ocupar um lugar estratégico no âmbito do Serviço Social e nas suas produções de conhecimentos, assim como no trabalho profissional, uma vez que as lutas sociais dos povos indígenas traduzem o que temos tido de resistência e de movimento contra-hegemônico ao que está posto pelo Estado brasileiro e suas estruturas jurídicas e políticas vigentes.

Assim, este artigo inicialmente discorre sobre as lutas sociais indígenas como forma de resistência diante das violações de seus direitos e como sendo expressão da questão social; e num segundo aspecto, procura dar visibilidade às políticas indigenistas já que os ataques a esses povos também tem relação à destituição de um conjunto de legislações no âmbito da proteção social brasileira, mas que ainda "[...] estão num desencontro no atendimento das necessidades socioculturais de vida dos indígenas" (DOMINGOS, 2016, p. 7).

\section{AS LUTAS SOCIAIS INDÍGENAS COMO FORMA DE RESISTÊNCIA}

Os povos indígenas possuem diferentes formas de se expressarem, conforme suas etnias, línguas, crenças e tradições, sendo estes modos que os distinguem entre si, que em meio às suas vivências proferem diferentes expressões da questão social, tanto no que se refere às violações dos seus direitos, quanto nas resistências e lutas cotidianas em defesa do seu território.

Inicialmente é preciso reconhecer que há 519 anos se deu o processo de invasão e colonização do país por parte dos europeus, cujos efeitos sustentaram o processo de extermínio desses coletivos. Neste período, estima-se que viviam no território brasileiro mais de 1.000 povos, somando entre 2 e 4 milhões de pessoas segundo dados do Instituto Socioambiental (2018). Do ano de 1500 até a década de 1970 a população indígena brasileira decresceu acentuadamente e muitos povos foram extintos. O genocídio iniciou no período colonial com a formação de um estado-nação, quando houve o esbulho das terras indígenas e a maior parte não sobreviveu aos ataques e ao convívio com a população não indígena. A minoria sobrevivente buscou refúgio em terras espalhadas pelas regiões brasileiras, onde vivem os remanescentes dos seus antepassados até os dias atuais.

Temporalis, Brasília (DF), ano 19, n. 38, p. 70-86, jul./dez. 2019. | ISSN 2238-1856 
Outro aspecto importante sobre a dimensão sócio-histórica, refere-se à criação do órgão indigenista oficial que se deu a partir de 1910, com o Serviço de Proteção ao Índio -SPI, a União passa a ter a responsabilidade sobre a assistência e proteção aos indígenas. Entretanto, é preciso exaltar que a própria SPI está relacionada por muitos desses ataques aos indígenas. De acordo com a Comissão Nacional da Verdade (2014), estima-se que dos "[...] 700 funcionários da SPI existentes na época, 134 eram acusados de praticar crimes contra os índios" (COMISSÃO NACIONAL DA VERDADE, 2014, p. 238). Neste contexto de denúncias de maus tratos e corrupções houve a extinção do SPI em 1967, dando origem à FUNAI, que em meio a sua criação no período militar até os dias atuais, sobrevive às ameaças de sua extinção.

Mesmo sem a intenção de percorrermos a linha do tempo e dos fatos que sustentaram o processo de extermínio, tutela e integração à comunhão nacional dos indígenas, é preciso frisar que após um longo período de ditadura militar somente com a $\mathrm{CF} / 88$, há o reconhecimento dos direitos originários e da ampliação de garantias destes coletivos. Entretanto de acordo com Domingos - assistente social Kaingang - "[...] nas tramas sociais, a existência de um passado de extermínio, imposição de vidas e ideologias não são reconhecidos, ao contrário são muitas vezes invisíveis para a sociedade atual" (DOMINGOS, 2016, p. 7).

Outro aspecto importante atribuído pelos não indígenas, trata-se da relação dos povos originários como sendo verdadeiros colonos do Brasil, verdadeiros donos dessas terras e primeiros habitantes do Brasil. A ideia de donos dessas terras carrega uma noção capitalista de posse, na qual a terra pertence ao indígena como propriedade privada (FERNANDES, 2018). A privatização da terra como meio de produção exclusivo de seu dono consolidouse no Brasil posteriormente à colonização, não sendo cabível pensar o indígena como proprietário original da terra segundo esse modelo econômico. A relação com a terra não se dá através da posse individual, mas do usufruto comunitário entre os indígenas e, fundamentalmente, de preservação e sobrevivência. As políticas de demarcação de terra são reivindicações indígenas, mas surgiram devido à invasão de suas terras e ao desrespeito de seus modos de vida, sendo, portanto, necessário que eles lutassem para se demarcar uma faixa territorial na qual pudessem vivenciar suas culturas sem serem atacados.

O território é parte indissociável dos seus modos de vida, portanto não é apenas fonte da subsistência material, mas é também lugar onde esses coletivos constroem sua realidade social e simbólica. Ambiente este, necessário para a reprodução física e cultural dos indígenas conforme cada etnia. Nesse sentido, “[...] a propriedade privada não cabe na concepção indígena de terra e território" (MUSEU DO ÍNDIO, [2019b]). Assim, a ideia de posse da terra não é uma ideia indígena, mas a demarcação dos seus territórios é um direito indígena e, portanto, um direito reclamável e a ser efetivado e defendido (FERNANDES, 2018).

A proposta de retirada do Ministério da Justiça da demarcação de terras e a não continuidade destas demarcações se constituem em um dispositivo para acirrar os conflitos e situações de riscos que atentam a vida dos indígenas. Além disto, o artigo 14 da convenção n 169 da Organização Internacional do Trabalho - OIT (2004) reconhece "[...] aos povos interessados os direitos de propriedade e de posse sobre as terras que tradicionalmente ocupam" (BRASIL, 2004a, não paginado). Isto é bastante contraditório,

Temporalis, Brasília (DF), ano 19, n. 38, p. 70-86, jul./dez. 2019. | ISSN 2238-1856 


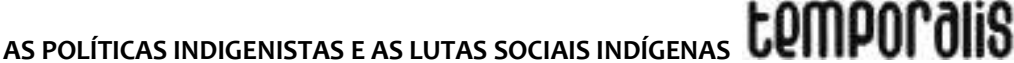

pois o que está em vigência no Brasil é um projeto que tem na sua base “[...] a banalização do humano, a descartabilidade e indiferença perante o outro, o que se encontra na raiz das novas configurações da questão social na era das finanças" (IAMAMOTO, 2008, p. 125).

Também além das demarcações, é intensiva a luta pela manutenção do subsistema de Saúde Indígena do SUS, operacionalizado pela Secretaria Especial de Saúde Indígena (SESAI) que está em processo de revisão pelo Governo Federal. Além disto, conflitos recentes e denúncias como no caso da morte do cacique da etnia Wajãpi (no dia 28 de julho de 2019) acirram a problemática sobre as invasões nas Terras Indígenas por conta do infringimento da legislação indigenista (BRASIL, [1937-2017]) cada vez mais ameaçada no contexto socioeconômico existente.

Diante deste cenário, as situações vivenciadas pelos povos indígenas não podem ser naturalizadas, é preciso considerá-las como sendo expressões da questão social e, portanto, não como algo estático, isolado, mas sim como resultado de um processo histórico de conflitos que emergem das desigualdades sociais e dos processos de produção e reprodução do capital. A questão social se metamorfoseia de diferentes formas, assim como, por meio da violência que tem no "[...] aparato repressivo do Estado, capturado pelas finanças e colocado a serviço da propriedade e poder dos que dominam, o seu escudo de proteção e de disseminação" (IAMAMOTO, 2008, p. 145). Ou ainda, nas palavras de Wanderley, são modalidades que se expressam na forma de gestão do Estado, nas políticas sociais, e pelo “[...] chamado 'princípio de exclusão', que se concretiza tanto da parte dos excluídos do processo produtivo do trabalho salariado, quanto da parte dos excluídos pela origem étnica, pela identidade cultural e pelas relações de gênero" (WANDERLEY, 2004, p. 59).

Contudo, é preciso assinalar que a questão social é mais do que as situações de pobreza, de vulnerabilidades ou exclusões, ela é desigualdade social sim, mas também “[...] atesta a radicalidade da alienação [...]. A subordinação da sociabilidade humana às coisas - ao capital-dinheiro e ao capital mercadoria -, retrata na contemporaneidade, um desenvolvimento econômico que se traduz como barbárie social" (IAMAMOTO, 2008, p. 125). Ao fazer essa referência verifica-se que a gênese da questão social está no processo de acumulação ou da reprodução do capital, que produz, ao mesmo tempo, uma acumulação de miséria, de disparidades econômicas, políticas e culturais das classes sociais.

Para Wanderlei (2004, p. 58), “[...] a questão social fundante, permanece vigindo sob formas variáveis [...]”, por isto a importância de compreendê-la e datá-la de modos distintos considerando as suas particularidades. Para o autor na America latina, questão social, que "[...] se põe, no espaço e no tempo, diferentemente da realidade europeia [...]" (WANDERLEI, 2004, p. 61) e com dimensões históricas, econômicas, sociais, políticas, religiosas e culturais que são próprias de suas nacionalidades, como têm sido os ataques aos povos indígenas em solo brasileiro. Este é um cenário de extremas desigualdades e injustiças, de concentração de renda, de poder, de pobreza das maiorias populacionais "[...] cujos impactos alcançam todas as dimensões da vida social, do cotidiano às determinações estruturais" (WANDERLEI, 2004, p. 58). 
É então neste contexto de disputas de toda ordem que diferentes coletivos por meio de movimentos de resistência se expressam contra aqueles que colonizam, excluem, exploram, discriminam e que detém financeiramente e, muitas vezes, politicamente o poder. Para Domingos (2016), esses são movimentos contra-hegemônicos que contestam e resistem contra a ideologia dominante pautadas no neoliberalismo e na ótica de exploração do capital. São movimentos indígenas que "[...] contribuíram com a defesa das necessidades e interesses dos coletivos [...] o movimento que desde a colonização foi de retomada de territórios tradicionais, luta esta que perdura até os dias de hoje" (DOMINGOS, 2016, p. 14).

Assim, a luta dos coletivos indígenas de várias etnias do Brasil, pode garantir na CF/88, seus direitos, não mais como uma política assimilassionista e integracionista, mas sim do direito a permanecerem e retomarem as suas terras tradicionais, e do direito ao reconhecimento de suas diferenças, conforme registros dos Artigos 231 e 232:

Art. 231: São reconhecidos aos índios sua organização social, costumes, línguas, crenças e tradições, e os direitos originários sobre as terras que tradicionalmente ocupam, competindo à União demarcá-las, proteger e fazer respeitar todos os seus bens. [...]; Art. 232: Os índios, suas comunidades e organizações são partes legítimas para ingressar em juízo em defesa de seus direitos e interesses, intervindo o Ministério Público em todos os atos do processo (BRASIL, 1988, não paginado).

Certamente esta trajetória requer uma reflexão crítica, para entender na contemporaneidade esses coletivos indígenas e suas resistências, uma vez que os modos de ser indígena estão relacionados com uma história de luta cotidiana de defesa dos seus direitos, pois conforme estudos de Fernandes (2018) as narrativas dos não indígenas referem:

\footnotetext{
Ser índio é... resistência, é ter amor à sua cultura a continuar repassando ela para as suas crianças (futuro); é luta por tantos direitos que lhe foram tirados, explorados, roubados, destruídos, é ter sabedoria ao nos mostrar que sem a Mãe Natureza não somos nada [...] Vislumbrar um mundo amplo fora das agressões violentas do Estado. Possibilidade de direitos, como educação indígena nas universidades públicas. Logo, uma constante luta por respeito e liberdade[..]Temos muito que aprender sobre 'o que é ser índio' [...]. É ser retirado da sua terra e ter que lutar para se manter vivo. Resistência (FERNANDES, 2018, p. 31-33).
}

Ainda é preciso reconhecer que as manifestações de resistências dos indígenas vêm crescendo ao mesmo tempo em que as violações também aumentam, como forma de denúncia e visibilidade dos direitos indigenistas. A $1^{\mathrm{a}}$ Marcha das Mulheres Indígenas (agosto de 2019 em Brasília), com o tema: Território: nosso corpo, nosso espírito, é fruto da luta por reconhecimento e espaço dentro dos movimentos indígenas e perante a sociedade brasileira. Entre as diversas pautas tratadas, destacamos a ocupação do prédio do Ministério da Saúde reivindicando a defesa do subsistema de saúde indígena amparado pela SESAI, que está ameaçada a vir a ser municipalizada trazendo graves consequências para a saúde destes povos (SCART; MAGNO, 2019). Essa marcha foi uma concretização de uma das deliberações do Acampamento Terra Livre-ATL (abril de 2019, em Brasília). O ATL é considerada a maior mobilização indígena do país que vem acontecendo nos últimos 15 anos, envolvendo movimentos sociais e organizações que representam os povos indígenas do Brasil e as principais lideranças com objetivo de levarem suas reivindicações aos poderes

Temporalis, Brasília (DF), ano 19, n. 38, p. 70-86, jul./dez. 2019. | ISSN 2238-1856 
Legislativo, Executivo e Judiciário, assim como disseminar para estudantes, imprensa e outros segmentos da sociedade informações qualificadas sobre a realidade das comunidades tradicionais no país, combatendo preconceitos e estereótipos (ARTICULAÇÃO DOS POVOS INDÍGENAS DO BRASIL, [2019]), além da necessária defesa e ampliação das políticas indigenistas.

\section{SOBRE AS POLÍTICAS INDIGENISTAS NAS POLÍTICAS SOCIAIS BRASILEIRAS}

Ao discorrermos sobre as políticas indigenistas e seus direitos, é importante dar luz inicialmente ao Estatuto do Índio implementado em meio à ditadura militar na década de 1970 e que teve como objetivo regular a situação jurídica dos índios e suas comunidades. Esse estatuto, ainda vigente, traz em seu texto termos e disposições há anos defasadas partindo do pressuposto etnocêntrico exposto, por exemplo, na incumbência à União, por meio da FUNAI, a tutela sobre os índios e suas comunidades. No entanto, o regime de tutela previsto pelo estatuto e promovido pela FUNAI se extingue com a CF/88, “[...] indicando novos parâmetros para a relação do Estado e da sociedade brasileira com os indígenas" (SOARES, 2014, p. 141). Além disto,é reconhecida a capacidade processual das comunidades e das organizações indígenas para a defesa dos próprios interesses e direitos, atribuindo a responsabilidade ao Ministério Público de garanti-los e intervir em todo e qualquer processo judicial, sob a competência da Justiça Federal.

Entretanto, é preciso reconhecer que a concretização da ruptura com as práticas tuteladoras e de opressão aos indígenas, ainda é um processo em curso de acordo com a própria FUNAI (2019a). Processo esse que vem provocando diferentes reflexões no ambiente acadêmico, nos movimentos indígenas, no âmbito das políticas sociais e em diferentes segmentos da sociedade que se encontram comprometidas com as lutas indígenas.

Diante do exposto e do reconhecimento constitucional, é preciso afirmar que historicamente os Povos Indígenas ficaram por décadas sem acesso às políticas sociais no Brasil no que se refere ao território, à saúde, à previdência, à educação, e à assistência social. Para o Museu do Índio (2019a), com o advento da carta magna - no capítulo específico denominado Dos Índios - inaugura-se uma nova fase do indigenismo estatal, mas que ainda não rompeu radicalmente com os valores etnocêntricos que contribuíram para reforçar assimetrias históricas nas relações entre o Estado e os povos indígenas, tão presentes no cenário brasileiro.

Tratar sobre política indigenista significa compreendê-las a partir das iniciativas formuladas pelas diferentes esferas do Estado brasileiro a respeito das populações indígenas.A formulação e a implementação de políticas públicas, voltadas para os povos indígenas são advindas de princípios que são parte do corolário de conjunto de leis internacionais e nacionais que garantem o direito dos indígenas a sua autodeterminação e, enquanto povos culturalmente diferenciados devem ser respeitados como tal (SOARES, 2012). Entretanto as políticas sociais ainda na maioria das vezes acabam classificando os indígenas também como excluídos, sendo este um termo trazido por Castel (2005) de utilização e aplicação inadequada para definir todas as modalidades de miséria, opressões e explorações do mundo contemporâneo. Da mesma forma, é preciso reconhecer os direitos indígenas e a forma como os acessam.

Temporalis, Brasília (DF), ano 19, n. 38, p. 70-86, jul./dez. 2019. | ISSN 2238-1856 
Deste modo, o trato teórico sobre os direitos de acordo com Couto (2010) requer a sua compreensão a partir da sua conformação por gerações, ou melhor por períodos sóciohistóricos, sendo que:os de primeira geração, são considerados os direitos civis e políticos que são exercidos pelos homens individualmente, busca opor-se a presença do Estado, pois o homem dotado de liberdade que deve ser o titular dos direitos civis; já os de segunda geração são os direitos sociais onde o homem e mulheres os detém através da intervenção do Estado, sendo o estado garantidor desses direitos. Esses direitos vêm se constituindo desde o século XIX, mas ganharam força no século XX. Busca a igualdade a fim de enfrentar as desigualdades sociais; e os direitos de terceira geração que vêm ganhando força desde o século $\mathrm{XX}$, pois visam o direito ao desenvolvimento, ao meio ambiente $e a$ autodeterminação dos povos (COUTO, 2010). Esses direitos de terceira geração se estabelecem a partir da ideia de solidariedade, onde nesta há o coletivo, pois não é apenas o indivíduo que o assume, mas as famílias, povos, grupos, nações que o querem. Eles são entendidos como respostas as opressões políticas e econômicas, os quais suas consequências fazem com que os movimentos assumam de forma coletiva para enfrentamento da realidade. É realizado por pactos entre os povos e organismos internacionais, como por exemplo, a ONU. É nesta última geração que se encontram os direitos indígenas, uma conquista a ser defendida e ampliada, assim como outras lutas de movimentos sociais: quilombolas, mulheres, LGBTs, entre outros.

Entretanto o que nos interessa aqui, é trazer aspectos do alinhamento da política indigenista brasileira com os principais marcos jurídicos nacionais e internacionais e que sinalizam o papel do estado na defesa, garantia e proteção dos direitos desses povos e ainda, superar "[...] práticas assistencialistas e tutelares, caracterizadas por relações patrimonialistas e clientelistas, de troca de favor, que contribuíram para agravar preconceitos, diferenças e desigualdades na relação dos povos indígenas com o Estado e a sociedade brasileira" (FUNAI, 2019b, não paginado). Assim, o Decreto 7.056, de 28 de dezembro de 2009, que se refere à proteção e à promoção dos direitos sociais dos povos indígenas se constituiu com base no entendimento de que as políticas sociais devem prever ações indigenistas assegurando: o respeito e a promoção das especificidades socioculturais e territoriais; o controle social e o protagonismo indígena, de modo que eles sejam capazes de intervir nos espaços institucionais de diálogo entre aspectos para formulação das políticas públicas (FUNAI, 2019b). É importante sublinhar que a promoção dos direitos sociais aos Povos Indígenas é ou deve ser realizada em articulação com diferentes políticas sociais públicas e, neste contexto, a intersetorialidade é uma dimensão fundamental para o desenvolvimento das ações.

Ainda sobre os direitos sociais, de acordo com a FUNAI é diretriz a "[...] garantia e qualificação da acessibilidade dos povos indígenas às políticas sociais se dá mediante a realização de consultas prévias, livres e informadas, cabendo-lhes a decisão de participar ou não de qualquer política" (FUNAI, 2019, não paginado). Entretanto, como toda e qualquer política social, que por meio dos seus programas, projetos e serviços materializam os direitos sociais, devem ser compreendidas como processos contraditórios. Isto pressupõe a apropriação conceitual e teórica sobre política social, o que nem sempre é uma realidade entre aqueles que colocam a engrenagem dos serviços, programas, projetos e políticas públicas em funcionamento.

É importante que se diga que, mesmo diante de tantas utilizações conceituais e compreensões sobre o significado das políticas sociais, estaremos sempre favorecendo 


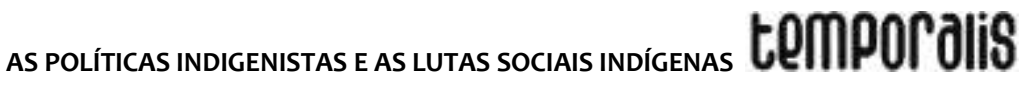

uma ou outra situação, para o “bem ou para o mal”, como nos alerta Mészáros (2008), pois não é possível trabalhar no âmbito das políticas sociais sem apreendê-la nos seus aspectos positivos e negativos. Sem entender o que se deve ou não defender para que realmente se possa ter "[...] como perspectiva a satisfação das necessidades sociais [...]", conforme o citado por Pereira (2011, p. 204), em páginas conclusivas de suas reflexões sobre a temática.

Ainda de acordo com Pereira a complexidade atribuída a política social não permite compreendê-la de forma linear, de conotação exclusiva "[...] positiva ou negativa, ou a serviço desta ou daquela classe” (PEREIRA, 2011, p. 166).

$\mathrm{Na}$ realidade, ela tem se mostrado simultaneamente positiva e negativa e beneficiado interesses contrários de acordo com a correlação de forças prevalecentes. É isso que torna a política social dialeticamente contraditória. E é essa contradição que permite à classe trabalhadora e aos pobres em geral também utilizá-la a seu favor (PEREIRA, 2011, p. 186).

Ainda se faz necessário trazer o entendimento sobre políticas indigenistas, na qual seus princípios e metas foram estabelecidos no $1^{\circ}$ Congresso Indigenista Interamericano, realizado, no México, em 1940. Chama-se de política indigenista as iniciativas formuladas pelas diferentes esferas do Estado brasileiro a respeito das populações indígenas.Política indigenista e indigenismo são categorias históricas, noções empregadas essencialmente no século 20, que formulam os princípios e metas transformados em práticas - ou políticas indigenistas - pelos países do continente americano. Assim, o principal objetivo da política indigenista hoje é a preservação das culturas indígenas, através da garantia de suas terras e o desenvolvimento de atividades educacionais e sanitárias (MUSEU DO ÍNDIO, 2019a).

Com o que vimos até aqui, nos aproximamos de algumas legislações no âmbito da seguridade social ampliada em que os indígenas estão com seus direitos específicos estabelecidos e, portanto, requerem nossa atenção. Na educação destacamos a Lei de Diretrizes e Bases da Educação Nacional-LDB 9.394 (BRASIL, 1996) que é um marco legal para a estruturação de uma educação escolar indígena intercultural, bilíngue e diferenciada na qual se instituiu a possibilidade da escola indígena contribuir para o processo de afirmação étnica e cultural desses povos (GRUPIONI, 2019). Também, a LDB determina a articulação dos sistemas de ensino para a elaboração de programas integrados de ensino e pesquisa, envolvendo a participação das comunidades indígenas em sua formulação, desenvolvendo currículos específicos, com conteúdos culturais correspondentes às respectivas comunidades e às suas particularidades locais para a materialização de uma educação específica para estes povos.

A política de saúde para os povos indígenas tem sido bastante evidenciada pelas organizações indígenas em função das violações que vêm ocorrendo por meio da criação de decreto presidencial que enfraquece a atuação da SESAI, responsável "[...] por coordenar e executar a Política Nacional de Atenção à Saúde dos Povos Indígenas e todo o processo de gestão do Subsistema de Atenção à Saúde Indígena (SasiSUS) no Sistema Único de Saúde (SUS)" (BRASIL, 2015, não paginado). Segundo a Organização Povos Indígenas do Brasil (2019), a política de saúde é uma das questões mais "[...] delicadas e problemáticas da Política Indigenista oficial [...]" (BRASIL, 2019), considerando a vulnerabilidade social e econômica e que estes povos estão susceptíveis as enfermidades

Temporalis, Brasília (DF), ano 19, n. 38, p. 70-86, jul./dez. 2019. | ISSN 2238-1856 
decorrentes ao contato com não indígenas, bem como a localização geográfica de regiões que habitam que são de difícil acesso.

A Política Nacional de Atenção à Saúde dos Povos Indígenas (PNASPI) (BRASIL, 2002) tratase de um modelo complementar e diferenciado de organização dos serviços de saúde, voltados para a proteção, promoção e recuperação da saúde. Para sua efetivação,é fundamental a existência de uma rede de serviços nas terras indígenas, de forma a superar as deficiências de cobertura, acesso e aceitabilidade do SUS para essa população. Desta forma, é indispensável medidas que viabilizem "[...] o aperfeiçoamento do funcionamento e a adequação da capacidade do Sistema, tornando possível e eficaz a aplicação dos princípios e diretrizes da descentralização, universalidade, eqüidade, participação comunitária e controle social” (BRASIL, 2002, não paginado). Assim a criação da SESAI, veio atender a uma antiga reivindicação dos povos indígenas, com o objetivo de implementar um novo modelo de gestão e de atenção no âmbito do Subsistema de Atenção à Saúde Indígena, articulado com o SUS (SasiSUS), descentralizado, com autonomia administrativa, orçamentária, financeira e responsabilidade sanitária dos 34 Distritos Sanitários Especiais Indígenas (DSEls). Contudo, os serviços de saúde específicos para esta população que deveriam ser ampliados e fortalecidos estão sob constante ameaça de extinção e precarização, como o impacto gerado pelo rompimento do Programa Mais Médico (2013-2019) que atendia aldeias de todas as regiões do Brasil.

Em relação à Previdência Social aos povos indígenas, eles se inserem na classificação de Segurado Especial conforme Instrução Normativa $n^{\circ} 45$ do INSS de 06 de agosto de 2010, Art. $7^{\circ}$ :

$\S 3^{\circ}$ Enquadra-se como segurado especial o índio reconhecido pela Fundação Nacional do Índio - FUNAl, inclusive o artesão que utilize matéria-prima proveniente de extrativismo vegetal, desde que atendidos os demais requisitos constantes no inciso $\mathrm{V}$ do $\S 4^{\circ}$ deste artigo, independentemente do local onde resida ou exerça suas atividades, sendo irrelevante a definição de indígena aldeado, indígena não-aldeado, índio em vias de integração, índio isolado ou índio integrado, desde que exerça a atividade rural em regime de economia familiar e faça dessas atividades o principal meio de vida e de sustento (INSTRUÇÃO NORMATIVA ${ }^{\circ} 45$ do INSS, Art. $7^{\circ}, \S 3^{\circ}, 2010$ ).

A previdência de maneira geral garante ao indígena o direito a benefícios próprios e para sua família, como aposentadoria por idade ou invalidez, auxilio doença, auxilio invalidez, pensão por morte, salário maternidade e auxílio reclusão. Para acessarem aos benefícios, necessitam obter certidão de nascimento civil, carteira de identidade, CPF, certidão de nascimento dos filhos, certidão de casamento e declaração de atividade rural que é fornecida pela FUNAI e homologada pelo INSS.

O tempo de contribuição para aposentadoria ocorre da seguinte forma: o indígena que começou a trabalhar anterior ao ano de 1991 precisa comprovar 12 anos de atividade rural em economia familiar e ser for do sexo masculino 60 anos de idade ou se for do sexo feminino 55 anos. Caso tenha iniciado a trabalhar posteriormente ao ano de 1991, deve comprovar 15 anos de atividade rural. Para o encaminhamento de salário maternidade, a comprovação do exercício da atividade rural deve ser de dez meses anteriores ao parto.

O indígena perde a condição de segurado especial quando exerce outra atividade remunerada, que é bastante comum nas aldeias trabalharem como professores, 
merendeiras, agente de saúde e saneamento, entre outros tipos de trabalho. Como geralmente estes empregos são temporários, no período em que o indígena esteja em alguma outra atividade que não seja a atividade rural exclusivamente, é desenquadrado da modalidade especial. Ao mesmo tempo em que a lei garante o enquadramento do indígena, acaba por restringir o acesso das mulheres indígenas menores de 16 anos quando recebem seus pedidos de concessão do benefício previdenciário salário-maternidade indeferidos. Nestes casos, é importante a orientação dos servidores da FUNAI aos indígenas para buscarem seus direitos no MPF da sua região, para que o mesmo mova ação civil pública com pedido de liminar, para que o INSS se abstenha de negar o saláriomaternidade às indígenas menores de 16 anos como forma de reconhecimento das diferenças e da visão multicultural.

Diante das dificuldades enfrentadas pelas populações indígenas na garantia do direito previdenciário, assim como da classe trabalhadora em geral, salientamos ainda os impactos da Reforma da Previdência proposta por meio da Emenda Constitucional n. 06/2019, do Poder Executivo, que "[...] modifica o sistema de previdência social, estabelece regras de transição e disposições transitórias, e dá outras providências" (BRASIL, 2019C, 1). Tais alterações são negativas para a população em geral e para os povos indígenas, segundo o Coordenador Geral da ARTICULAÇÃO DOS POVOS INDÍGENAS DO BRASIL (APIB), Tupinikim (2019), pois muitos não conseguirão cumprir as exigências e serão deslocados para o Benefício de Prestação Continuada. Ressalta ainda que é desigual este tratamento "que não leva em consideração a realidade do mundo do trabalho, como, por exemplo, ao igualar a idade de aposentadoria de homens e mulheres e ao não considerar as diferenças entre o trabalho no mundo urbano e no campo" (ARTICULAÇÃO DOS POVOS INDÍGENAS DO BRASIL, [2019]).

Já na Assistência Social, o artigo 194 da CF /88 (BRASIL, 1988) e a Lei Orgânica de Assistência Social (LOAS, 1993), tem como princípios o atendimento das necessidades sociais da população, a universalização dos direitos sociais, o respeito à cidadania, autonomia e à convivência familiar e comunitária e a igualdade de direitos, sem discriminação de qualquer natureza. É a partir da Política Nacional de Assistência Social (PNAS) (BRASIL, 2004b). que iniciam-se ações direcionadas para os indígenas visando combater a extrema pobreza e incluindo esses coletivos nos programas de transferência de renda, como o Programa Bolsa Família, entre outros (QUERMES; CARVALHO, 2013). No processo de consolidação da política de assistência social, aos poucos vai se dando destaque à necessidade de levar em conta as especificidades dos indígenas o que vai requerer uma equipe técnica qualificada para melhor intervenção com esses grupos, no sentido de promover a inclusão sem fragilizar seus valores éticos e culturais.

O documento Trabalho Social Com Famílias Indígenas: Proteção Social Básica Para Uma Oferta Culturalmente Adequada (BRASIL, 2016) aponta subsídios teóricos e técnicos para apoiar as equipes de referência do SUAS, em particular, as equipes dos Centros de Referência de Assistência Social (CRAS) no desenvolvimento do Serviço de Proteção e Atendimento Integral à Família (PAIF), com famílias e comunidades indígenas. Tal publicação, recomenda que

[...] a equipe do CRAS deve contar com o consentimento das famílias antes de iniciar as ações, bem como com sua participação na definição das mesmas. Paralelamente as lideranças indígenas são o canal de comunicação obrigatório

Temporalis, Brasília (DF), ano 19, n. 38, p. 70-86, jul./dez. 2019. | ISSN 2238-1856 
para apresentação do CRAS e do PAIF e negociação antes da implementação das ações socioassistenciais no interior das aldeias (BRASIL, 2016, p. 37).

Assim, tendo como parâmetros teórico-metodológicos e técnico-operativos, o trabalho social com famílias indígenas comporta: consciência crítica e espírito investigativo por parte dos profissionais do CRAS acerca da realidade indígena local; equipe de referência interdisciplinar e/ou indigenista experiente entre outros; adoção de abordagem e procedimentos metodológicos pautados no diálogo e no respeito intercultural; conhecimento do território (potencialidades, recursos, vulnerabilidades) e da cultura (tradições,organização social e parentesco, visão de mundo) do(s) povo(s) indígena(s) que ali habita(m); planejamento e análise das ações desenvolvidas; promoção da participação dos indígenas no planejamento e avaliação das ações do PAIF(BRASIL, 2016).

Como visto o atendimento diferenciado para as populações indígenas no SUAS, requer avanços, garantindo a participação dos indígenas para compor a política indigenista, o aprimoramento do trabalho intersetorial entre órgãos que atuam nas temáticas indígenas no intuito da ampliação das políticas específicas para esta população, assim como, a inserção dos trabalhadores desta política em processos de educação permanente.

\section{REFLEXÔES FINAIS}

Sem a pretensão de esgotar a discussão desta temática, o intuito por meio desta sistematização foi o de afirmar a relevância da aproximação dos trabalhadores inseridos nas políticas sociais públicas, em especial os assistentes sociais, com a questão indígena. Trata-se de um cenário, em parte aqui problematizado, que exige do Serviço Social não somente o conhecimento desta realidade, mas a transformação da mesma por meio do trabalho profissional e fundamentalmente, pelo compromisso ético e político com a defesa dos direitos humanos e, portanto, indigenistas. Sabemos que a produção do conhecimento na área sobre a questão indígena, ainda é bastante incipiente. Entretanto, é preciso conhecer e investigar e até militar pela causa indígena, pois esses povos trazem nas suas lutas sociais, nas suas memórias e histórias, nos seus modos de ser, viver e conhecer, culturas e necessidades humanas que exigem mediações por parte do trabalho dos trabalhadores que atuam no âmbito das políticas sociais. Contudo, a fragilidade teórica dissociada dos fundamentos do Serviço Social, a tutela, a postura conservadora, ou, ainda, a pouca clareza das contradições das políticas sociais e, neste caso, as indigenistas, é algo recorrente entre os profissionais. Aqui, salientamos o desconhecimento e o estranhamento de muitos trabalhadores, que atuam no âmbito das políticas sociais, sobre os povos indígenas e as relações interculturais e, muitas vezes, em vez de defender e atender às necessidades desses sujeitos de direitos, desconsideram às suas culturas e trajetórias sócio-históricas. Ademais, é preciso reconhecer que as lutas históricas entre os indígenas e não indígenas são decorrentes do colonialismo espanhol e português e das fórmulas de organização estabelecidas pelo imperialismo inglês, "[...] estando à economia e a sociedade influenciada pelo mercantilismo, o escravismo, a grande propriedade e as civilizações indígenas" (IANNI, 2003, p. 49). Para tanto, não há como superar essas práticas se não estivermos abertos a conhecer e refletir juntamente com esses povos suas reais necessidades para que então a mediação destes direitos possa ocorrer por meio do trabalho profissional e das lutas sociais.

Temporalis, Brasília (DF), ano 19, n. 38, p. 70-86, jul./dez. 2019. | ISSN 2238-1856 
Portanto, se as competências profissionais se revelam por meio do trabalho concreto efetivando respostas à questão social - base fundante da profissão - cada vez mais a construção de um perfil profissional generalista que apreenda de forma critica e totalizante os processos sociais, se faz necessária (ASSOCIAÇÃO BRASILEIRA DE ENSINO E PESQUISA EM SERVIÇO SOCIAL, 1996). O foco nas lutas sociais e violações de direitos dos indígenas é uma estratégia para afirmação desta pauta na agenda do Serviço Social como desdobramentos das questões étnico-raciais. Os mecanismos de mobilização indígena nos interessam, pois o protagonismo desses povos possibilitam contribuir com a ampliação das resistências e defesa não somente dos direitos indígenas, mas da classe trabalhadora cotidianamente afrontada no cenário sócio-histórico em solo brasileiro.

\section{REFERÊNCIAS}

ASSOCIAÇÃO BRASILEIRA DE ENSINO E PESQUISA EM SERVIÇO SOCIAL. Diretrizes gerais para o curso de Serviço Social. Rio de Janeiro: ABEPSS, 1996. Disponível em: http://www.abepss.org.br/arquivos/textos/documento_201603311138166377210.pdf. Acesso em: 10 ago. 2019.

ARTICULAÇÃO DOS POVOS INDÍGENAS DO BRASIL. [S. I.], [2019]. Disponível em: http://apib.info/apib/. Acesso em: 2 ago. 2019.

BRASIL. Fundação Nacional do Índio- FUNAI. Legislação Indigenista. [2019a]. Disponível em: http://www.funai.gov.br/index.php/servicos/legislacao. [Brasília (DF), 1937-2017]. Acesso em: 17 maio.2019.

BRASIL. Fundação Nacional do Índio- FUNAI. Direitos Sociais. [2019b].Disponível em: http://www.funai.gov.br/index.php/nossas-acoes/direitos-sociais. [Brasília (DF), 19372017]. Acesso em: 20 ago. 2019.

BRASIL. Proposta de Emenda à Constituição no. 6, de 2019 - Reforma da Previdência. Brasília (DF), ago. 2019c. Disponível em: https://legis.senado.leg.br/sdleggetter/documento?dm=7987584\&ts=1575987231093\&disposition=inline. Acesso em: 13 set. 2019.

BRASIL.Ministério do Desenvolvimento Social. Orientações Técnicas Trabalho Social com Famílias Indígenas. Proteção Social Básica para uma Oferta Culturalmente adequada. Brasília (DF), 2016.

BRASIL. Ministério da Saúde. Secretaria de Saúde Especial IndígenaSESAI. Desafios e potencialidades da análise geográfica em saúde na Secretaria Especial de Saúde Indígena-SESAI. Brasília (DF), 2015. Disponível em: http://www.saude.gov.br/sesai. Acesso em: 13 jul. 2019.

BRASIL. Lei de cotas - Lei Federal n 12.711, de 29 de agosto de 2012. Brasília (DF), 2012. BRASIL. Instrução Normativa Instituto Nacional do Seguro Social-INSS n 45, de 06 de agosto de 2012. Brasília (DF), 2010. 
BRASIL. Decreto $n^{\circ}$ 5.051, de 19 de abril de 2004: Promulga a Convenção $n^{\circ} 169$ da Organização Internacional do Trabalho- OIT sobre Povos Indígenas e Tribais. Brasília (DF), $2004 a$.

BRASIL. Ministério do Desenvolvimento Social e Combate à Fome. Secretaria Nacional de Assistência Social. Política Nacional de Assistência Social (PNAS). Brasília (DF), 2004b.

BRASIL. Ministério da Saúde. Fundação Nacional de Saúde-FUNASA. Política Nacional de Atenção à saúde dos povos indígenas. Aprovada pela Portaria do Ministério da Saúde $\mathbf{n}^{\circ}$ 254, de 31 de janeiro de 2002. Brasília (DF), 2002. Disponível em:

http://bvsms.saude.gov.br/bvs/publicacoes/sus_principios.pdf. Acesso em: 20 jul. 2019.

BRASIL. Lei de Diretrizes e Bases da Educação Nacional - LDB - Lei nº.394, de 20 de dezembro de 1996. Brasília (DF), 1996.

BRASIL. Lei Orgânica de Assistência Social (LOAS). Lei 8.742 de 7 de dezembro de 1994. Brasília, 1993.

BRASIL. Constituição (1988). Constituição da República Federativa do Brasil. Brasília (DF): Senado Federal: Centro Gráfico, 1988. Disponível em:

https://www.senado.leg.br/atividade/const/con1988/CON1988_05.10.1988/art_232_.asp. Acesso em 13 jun. 2019.

CASTEL, Robert. As Metamorfoses da Questão social: uma crônica do salário. São Paulo: Vozes, 2005.

COMISSÃO NACIONAL DA VERDADE. Relatório da Comissão Nacional da Verdade. Brasília (DF), 2014. Disponível em: https://amazoniareal.com.br/comissao-da-verdade-ao-menos83-mil-indios-foram-mortos-na-ditadura-militar/. Acesso em 13 jun. 2019.

COUTO, Berenice. O direito social e a assistência social na sociedade brasileira: uma equação possível? 4. ed. São Paulo: Cortez, 2010.

DOMINGOS, Angélica. (Ninhpryg). O bem viver Kaingang: perspectivas de um modo de vida para construção de políticas públicas aos coletivos indígenas. Trabalho de Conclusão de Curso do Serviço Social. Porto Alegre: UFRGS, 2016.

FERNANDES, Rosa M. Castilhos (org.). Relatório de Pesquisa Contribuições para Afirmação dos Direitos dos Estudantes Indígenas na Educação Superior: uma experiência de extensão e pesquisa. Porto Alegre: UFRGS, dez. 2018.

FERNANDES, Rosa Maria Castilhos; AMES, Valesca; DOMINGOS, Angélica. Encontros e Desencontros das Ações Afirmativas. Revista O Social em Questão, ano 20, n. 37, p. 7190, jan./abr. 2017.

IAMAMOTO, M. V. Serviço Social em tempo de capital fetiche: capital financeiro, trabalho e questão social. 3. ed. São Paulo: Cortez, 2008. 
IANNI, Otávio. Enigmas da Modernidade-Mundo. 3.ed. Rio de Janeiro: Civilização Brasileira,2003.

INSTITUTO BRASILEIRO DE GEOGRAFIA E ESTATÍSTICA. Censo população indígena 2010. Disponível em: https://indigenas.ibge.gov.br/ Acesso em: 19 ago. 2019.

INSTITUTO NACIONAL DE ESTUDOS E PESQUISAS EDUCACIONAIS ANÍSIO TEIXEIRA. Censo da Educação Superior 2016. Disponível em: http://portal.inep.gov.br/artigo/lasset_publisher/B4AQV9zFY7Bv/content/mec-e-inep-divulgam-dados-do-censo-daeducacao-superior-2016/21206. Acesso em: 19 ago. 2019.

INSTITUTO SOCIOAMBIENTAL. Quem São. [S. I.], 5 jun. 2018. Disponível em: https://pib.socioambiental.org/pt/Quem_s\%C3\%A30. Acesso em:18.ago.2019.

MÉSZÁROS, István. A Educação para Além do Capital. Tradução Isa Tavares. 2. ed. São Paulo: Boitempo, 2008.

MUSEU DO ÍNDIO. Política Indigenista. Rio de Janeiro, [2019a]. Disponível em: http://www.museudoindio.gov.br/educativo/pesquisa-escolar/241-politica-indigenista. Acesso em: 22 maio 2019.

MUSEU DO ÍNDIO.Território Indígena. Rio de Janeiro, [2019b]. Disponível em: http://www.museudoindio.gov.br/educativo/pesquisa-escolar/51-territorio-indigena. Acesso em 22.mai.2019

ONU.Organizações das Nacões Unidas. Relatório da missão ao Brasil da Relatora Especial sobre os direitos dos povos indígenas. Brasília (DF), 2016. Disponível em: http://www.mpf.mp.br/atuacao-tematica/ccr6/documentos-epublicacoes/docs/relatorio-onu-povos-indigenas/relatorio-onu-2016_pt.pdf/view. Acesso em: 22 maio 2018.

PEREIRA, Potyara A. Política Social: temas e questões. 3. ed. São Paulo: Cortez, 2011.

PUTTI, Alexandre. Bolsonaro: “Enquanto eu for presidente, não tem demarcação de terra indígena”. Carta Capital, São Paulo, 16 ago. 2019. Disponível em: https://www.cartacapital.com.br/politica/bolsonaro-enquanto-eu-for-presidente-naotem-demarcacao-de-terra-indigena/. Acesso em 18 ago.2019.

QUERMES, Paulo Afonso de Araújo; CARVALHO, J. A. Os impactos dos benefícios assitenciais para os povos indígenas: estudo de caso e, aldeias guaranis. Serviço Social \& Sociedade, v. 116, p. 769-791, out./dez. 2013.

SCART, Sofia; MAGNO, Nívea. Mulheres em luta: as principais pautas da $1^{\text {a }}$ Marcha das Mulheres Indígenas. Brasília (DF): CONSELHO INDIGENISTA MISSIONÁRIO; Mídia Ninja, 8 ago. 2019. Disponível em: https://cimi.org.br/2019/08/mulheres-em-luta-as-principaispautas-da-1a-marcha-das-mulheres-indigenas/. Acesso em: 18 ago. 2019.

SOARES, Mariana de Andrade. Caminhos para viver o Mbya Reko: Estudo 


\section{temporalis}

Antropológico do contato interétnico e de Políticas Públicas de Etnodesenvolvimento a partir de pesquisa etnográfica junto a coletivos Guarani no Rio Grande do Sul. 2012. Tese (Doutorado em Antropologia Social)-Programa de Pós-Graduação em Antropologia Social, UFRGS, Porto Alegre, 2012.

WANDERLEY, Luis Eduardo W. A questão social no contexto da globalização o caso latinoamericano e o caribenho. IN: BELFORE-WANDERLEY, Mariangela; BOGUS, Lucia; YASBEK, Maria Carmelita. Desigualdade e a questão social. São Paulo: EDUC, 2004. p.51-161.

Rosa Maria Castilhos Fernandes sistematizou o artigo a partir de estudos e revisão bibliográfica que subsidiam investigações que vêm sendo realizados no Grupo de Pesquisa Educação, Trabalho e Políticas Sociais da Universidade Federal do Rio Grande do Sul, coordenado pela autora.

Mestre e Doutora em Serviço Social pelo PPG Serviço Social PUCRS. Professora Adjunta e Pesquisadora do Departamento de Serviço Social e do PPG Política Social e Serviço Social da UFRGS. Bolsista Produtividade CNPq.

Mariana Martins Maciel co-autora, sistematizou o artigo realizando revisão bibliográfica, indicando referências e adensando a discussão sobre a temática.

Bacharel e Licenciada em Geografia. Professora de Escola Indígena. Mestranda do PPG Política Social e Serviço Social da Universidade Federal do Rio Grande do Sul. 